\title{
REPLANTEAMIENTO DEL PRESIDENCIALISMO EN HONDURAS: DESAFÍOS PARA EL BUEN EJERCICIO DEL PODER ESTATAL Y LA ESTABILIDAD DEMOCRÁTICA
}

\author{
RETHINKING PRESIDENTIALISM IN HONDURAS: CHALLENGES FOR A GOOD EXERCISE OF \\ STATE POWER AND DEMOCRATIC STABILITY
}

\section{RESUMEN}

Anny Lineth Matamoros Pineda ${ }^{1}$

DOI: https://doi.org/10.5377/lrd.v40i1.8906

La forma de gobierno que un Estado adopta determina el ejercicio y control del poder estatal. Honduras, al igual que la mayoría de países de Latinoamerica cuenta con un sistema presidencialista, el que es objeto de multiples críticas. Entre sus principales cuestionamientos se encuentra, la concentración del poder en el Ejecutivo en detrimento del resto de funciones básicas del Estado. En ese sentido, este artículo tiene por objeto el estudio doctrinal del presidencialismo, con el propósito de determinar si esta forma de gobierno es la más adecuada para Honduras. Para ello, se comparan los controles interorgánicos entre el presidencialismo y el parlamentarismo, este último, al ser una opción para el control del Ejecutivo y consecuentemente para la estabilidad democrática. Finalmente, se presenta el replanteamiento de la forma de gobierno en Honduras, a partir del análisis de su concepción y sus repercusiones en la interrelación entre las funciones básicas del Estado y los controles entre ellas.

PALABRAS CLAVES: Presidencialismo; parlamentarismo; forma de gobierno; función Ejecutiva; función Legislativa; función Judicial.

\section{ABSTRACT}

The form of government that a State adopts determines the exercise and control of state power. Honduras, like most Latin American countries, has a presidential system, which is the subject of multiple criticisms. Among its main questionings is the concentration of power in the Executive in detriment of the rest of the State branches. In that sense, this article aims the doctrinal study of presidentialism, with the purpose of determining whether this form of government is the most appropriate for Honduras. For this, the inter-organic controls between presidentialism and parliamentarism are compared, the latter, being an option for the control of the Executive and consequently for democratic stability. Finally, the rethinking of the form of government in Honduras is presented, based on the analysis of its conception and its repercussions on the interrelation between the basic functions of the State and the controls between them.

KEY WORDS: Presidencialism; parlamentarism; form of government; Executive branch; Legislative branch; Judicial branch.

Fecha de recepción: 01 de agosto del 2019

Fecha de aprobación: 01 de octubre del 2019

\footnotetext{
${ }^{1}$ Anny Lineth Matamoros Pineda, Máster en Derecho Constitucional de la Universidad de Valencia y Maestrante en Derecho Penal y Procesal Penal de la Universidad Autónoma de Honduras. Actualmente labora para la Organización de los Estados Americanos (OEA), Correo electrónico: annymatamorosp.8@gmail.com.
} 


\section{INTRODUCCIÓN}

De acuerdo a Karl Loewenstein, la decisión conformadora más importante con la que se enfrenta una nación en el ámbito interno, es la elección de su sistema político y la forma de gobierno ${ }^{2}$ bajo la cual desea vivir (p.19).

En la doctrina jurídica y política se pueden encontrar diversos conceptos de forma de gobierno, para efectos del presente estudio, se utilizará el concepto de Carlos Villabela Armengol (2008), al considerar que el mismo reúne los elementos importantes que la componen, al definirla como:

La organización que adoptan las instituciones supremas del poder que ejercen las funciones legislativa, ejecutiva y de gobierno, el modo de formación de sus eslabones supremos, sus roles dentro del Estado, las competencias que poseen, la dinámica de interrelación que se establece entre los mismos y la forma mediante la cual se conforma y produce en ellos el proceso de toma de decisiones a través del cual se personifica la voluntad estatal, siendo la solución jurídica - institucional que adopta el poder político en una nación y que se sintetiza en un modelo organizacional determinado (p.21).

Mediante la forma de gobierno, la sociedad determina la manera en que se organizan los órganos estatales para la toma de decisiones y la interrelación que estos mantienen entre sí, incluyendo las atribuciones de control inter orgánicas otorgadas

\footnotetext{
${ }^{2}$ Conforme a Loewenstein "El concepto "sistema político" no tiene el mismo significado que el concepto "forma de gobierno". Como concepto genérico, el término "sistema político" abarca por lo general una serie de tipos de gobierno que están unidos por la identidad o afinidad de sus ideologías y de las instituciones que a éstas corresponden. Así, el sistema político del constitucionalismo democrático incluye diversos tipos de gobierno que, según queda conformada la interacción de los diferentes detentadores del poder en la formación de la voluntad estatal, se institucionalizan como presidencialismo, parlamentarismo con supremacía de la asamblea o del gabinete, gobierno de asamblea, gobierno directorial, democracia directa o semidirecta... En virtud de una precisión terminológica, quede, pues, asentado que en la siguiente exposición el concepto «sistema político» se refiere a la estructura ideológica, mientras que el concepto «tipo de gobierno» o «régimen político» alude a la concreta conformación de las instituciones del sistema político en una determinada sociedad estatal."(Loewenstein, s.f.,p.4)
}

a cada una de ellas (Armengol, 2008). En otras palabras, es la forma en que se lleva a la práctica el ejercicio y control del poder estatal, pudiendo tener diversos matices, según la forma de gobierno que se trate y las diferentes modalidades que en cada país se adopten.

A lo largo de la historia han existido diferentes clasificaciones de forma de gobierno ${ }^{3}$, que toman como base diferentes variables. Desde una perspectiva contemporánea se han aceptado ampliamente (aunque con diferentes variaciones) las siguientes: Parlamentaria, ya sea monárquica o presidencial; presidencial; semi presidencial y la convencional ${ }^{4}$. Estos tipos de gobierno se estructuran de acuerdo a la organización que el Ejecutivo y el Legislativo adoptan.

En América Latina, la forma de gobierno ampliamente adoptada al independizarse de las colonias españolas fue el presidencialismo, Honduras ${ }^{3}$ Clasificación clásica: Platón en La República clasificó a los gobiernos en monarquía, aristocracia y democracia. Aristoteles en La Política agrupó a los gobiernos por sus formas puras e impuras, en las primeras identificó a la monarquía, la aristocracia y la democracia, mientras que en las segundas a la tiranía, oligarquía y oclocracia. Clasificación del pensamiento medieval: Tomás de Aquino en la Summa Theologiae reconoció a la monarquía, la aristocracia, la oligarquía, la democracia y la tiranía. Maquiavelo en El Principe habló de república, principado o monarquía. Locke en Tratado sobre el gobierno civil identificó a la república, la oligarquía y la monarquía. Montesquieu en El espíritu de las leyes agregó principios morales a sus tipos de gobierno, distinguiendo a la democracia comoo virtud; aristocracia con moderación, monarquía con honor y el depotismo como modalidad impura. Clasificación del pensamiento moderno: George Burdeau en Derecho Constitucional e instituciones políticas distinguió el régimen democratico (parlamentario presidencial, de asamblea), el régimen autoritario (cesarismo empírico, dictadura ideologica) y el régimen de poder individualizado. Karl Loewenstein en Teoría de la Constitución identificó el gobierno en democracia constitucional (gobierno de democracia directa, gobierno de asamblea, gobierno parlamentario, gobierno de gabinete, gobierno presidencial y gobierno directorial) y gobierno de autocracia (monarquía absoluta, cesarsmo plebiscitario y neopresidencialismo) (Villabela, 2008, p.24-25)

${ }^{4}$ También conocido como directorial y se ha desarrollado en Suiza y que tiene como características: la función Legislativa está en manos del Parlamento Federal y se instituye como órgano supremo del poder; El Ejecutivo es desempeñado por un órgano colegiado denominado Consejo Federal, integrado por siete miembros; El Consejo Federal es elegido por el Parlamento Federal y sus integrantes no pueden ser miembros del mismo; Cada miembro del Consejo Federal preside un ramo de la administración; El Consejo Federal es subordinado al Parlamento Federal y se proyecta como agencia suya; El Consejo Federal elige entre sus miembros a un Presidente y un Vicepresidente por el término de un (1) año y no pueden ser reelectos para el desempeño inmediato; $y$, el parlamento no puede ser disuelto por el Consejo bajo ninguna circunstancia. (Villabela, 2008, p. $70-72$ ) 
no fue excepción. Por lo que, en virtud del área objeto de estudio, el presente análisis se centrará en esta forma de gobierno, para posteriormente, hacer una comparación de los controles interorgánicos entre el presidencialismo y el parlamentarismo, este último considerado para muchos, la forma de gobierno que permite una mayor estabilidad del Estado democrático. Finalmente, se detallan los desafios del presidencialismo en Honduras para garantizar el buen ejercicio del poder estatal.

\section{METODOLOGÍA}

El tema objeto de estudio implica una revisión de los desarrollos teóricos y doctrinarios en la materia, así como de la legislación hondureña, especialmente del texto constitucional vigente, incluyendo algunos desarrollos jurisprudenciales. Para alcanzar el fin en mención, se utilizó el método deductivo e histórico bajo las técnicas y el enfoque de tipo descriptivo, normativo y propositivo.

\section{ADOPCIÓN EN LATINOAMÉRICA DEL SISTEMA PRESIDENCIALISTA}

Formalmente, el presidencialismo fue diseñado en Estados Unidos de América y ha sido ampliamente adoptado en la mayoría de los textos constitucionales de Latinoamérica. Para explicar la adopción de la república presidencial basada en el principio de separación de poderes por parte de la región latinoamericana, algunos estudiosos del tema como Gabriel Negretto (2013, p.128) señala que respondió a diversos factores históricos, como los siguientes:

1. La Constitución americana era el único ejemplo de presidencialismo y se presentaba como una república próspera y políticamente estable; $\mathrm{y}$,

2. En el contexto de pugnas internas entre liberales y conservadores, federalistas y centralistas, los países consideraron que los Ejecutivos colegiados y los Ejecutivos controlados por Asambleas Legislativas eran instrumentos inadecuados para proveer gobiernos estables.
No obstante, el predominio de esta forma de gobierno en la región, ha sido objeto de multiples críticas al atribuirle que el mismo respondió al caudillismo existente luego de la independencia. Y es que, la adopción en Latinoamérica del modelo norteamericano, tuvo algunas variaciones que fortalecían aún más el cargo presidencial; desde la duración en el cargo, los límites a la reelección, las atribuciones de gobierno, legislación y emergencia ${ }^{5}$ otorgadas al presidente (Negretto,2013). Por lo que, constantemente ha sido comparado con el parlamentarismo, al considerar que la mayoría de democracias estables responden a formas de gobierno parlamentarias.

Juan Linz (como se citó en Ackerman, 2011) señala que la forma de gobierno presidencialista y consecuentemente la interacción de las funciones estatales ha sido una de las exportaciones más peligrosas de los Estados Unidos, especialmente hacia el sur de la frontera, llegando a afirmar que: "el parlamentarismo generalmente ofrece una mejor esperanza para preservar la democracia” (Linz, 2013, p.12).

Para entender de mejor manera el presidencialismo como forma de gobierno, resulta necesario identificar sus características esenciales, las que de acuerdo al profesor Villabela (2008) son las siguientes: 1. El presidente funge como Jefe del Estado y de Gobierno, encabezando la función Ejecutiva; 2. El gabinete de Gobierno no llega a constituirse como un órgano autónomo e independiente del primero; 3 . El titular del Ejecutivo es elegido por sufragio directo, por lo que, junto al Legislativo se convierten en las instituciones con credibilidad popular; 4. Los secretarios de Estado son seleccionados y removidos libremente por el presidente entre personas de su confianza y pertenecientes a su línea política; 5 . Dentro del

5 "En el área de gobierno, la mayoría de las constituciones concedía al presidente el poder de nombrar unilateralmente a los ministros del gabinete, altos funcionarios administrativos, y cargos ejecutivos a nivel local; así como le otorgaba iniciativa y control sobre la intervención del ejército en conflictos internos o externos En materia de legislación, la mayoría de los presidentes recibió autoridad formal para presentar proyectos de ley en el congreso, además de la iniciativa exclusiva referente al presupuesto nacional, y la facultad de convocar al congreso a sesiones extraordinarias para deliberar sobre asuntos propuestos por el presidente Por último, un presidente típico en Hispanoamérica disfrutaba de poderes de emergencia discrecionales" (Negretto,2013, p.129). 
Gabinete todos los secretarios o ministros tienen el mismo rango; 6. El titular del Ejecutivo cuenta con un amplio espectro de funciones; 7. El titular del Ejecutivo tiene limitaciones para su prolongación en el cargo una vez que ha cumplido su mandato; y, 8 . El Parlamento ejerce control sobre la actividad de gobierno a través de mecanismos generales ${ }^{6}$.

En el caso del presidencialismo latinoamericano, formalmente se pueden identificar como principales características las siguientes:

1. Diseño a nivel constitucional de la función Ejecutiva con un amplio ámbito de competencias y poderes;

2. En el Ejecutivo participa un vicepresidente o designado presidencial ${ }^{7}$, encargado de asumir temporal o definitivamente la función Ejecutiva ante la ausencia del presidente;

3. La legitimación constitucional de la alternancia en la presidencia a través de diferentes variantes;

4. Desarrollo de una función Ejecutiva menos personalista, por medio de la conformación de un organismo colegiado "presidente y los ministros" o secretarios de Estado; y,

5. Diseño de la relación entre el Legislativo y el Ejecutivo basada en los checks and balances (Villabela, 2008).

A pesar de encontrarse características comunes en el presidencialismo, en Latinoamérica, en cada Estado existen diversos matices, ya que cada país ha adoptado una forma de gobierno conforme a su propio contexto. Es por ello que, las variaciones del presidencialismo en América Latina responden a variedad de condiciones políticas y económicas propias de cada país o subregión (México, Centroamérica y Suramérica), con intereses y actores diferentes.

\section{PRINCIPALES CRÍTICAS AL PRESIDENCIALISMO}

\footnotetext{
${ }^{6}$ Se consideran mecanismos generales, las atribuciones de interpelación, nombrar comisiones de investigación, aprobar o ratificar algunas decisiones del Ejecutivo, etc

${ }^{7}$ En El Salvador y Honduras la figura de vicepresidentes se encuentra bajo el nombre de designados presidenciales.
}

Las diversas críticas realizadas al presidencialismo generalmente parten de una contraposición al parlamentarismo. Entre estas, se encuentra la doble legitimidad democrática que esta forma de gobierno crea y que conlleva a conflictos entre la función Legislativa y Ejecutiva; sobre todo, cuando estas están dominadas por diferentes partidos o cuando al estar dominadas por un mismo partido existen fracturas o divisiones en este. Para Linz (2013), ante estos escenarios de conflicto: "no existe principio democrático alguno para resolver las disputas acerca de cuál de las dos partes representa realmente la voluntad del pueblo" (p.24). Este tipo de conflictos no solo podría generar una crisis institucional, sino que, también una crisis social al crear rivalidades que podrían trasladarse a la sociedad.

Bruce Ackerman (2011), señala que, ante el impasse entre la función Ejecutiva y Legislativa, se pueden presentar tres escenarios:

a). La negociación o la esperanza madisoniana: $\mathrm{Se}$ produce cuando el Legislativo y el Ejecutivo tratan de llegar a una combinación de razonamiento y negociación que da lugar a un conjunto de buenos resultados.

b). La ruptura constitucional: Cuando el Legislativo o el Ejecutivo al tratar de destruir al rival político, avasalla el sistema constitucional estableciendo caudillos con la ayuda de los militares o de plebiscitos extra constitucionales.

c). Crisis de gobernabilidad: Cuando en vez de una confrontación absoluta entre la función Ejecutiva y Legislativa, se establece una tendencia hacia las descalificaciones y calumnias, usando las herramientas constitucionales a su disposición para hacerse la vida difícil entre sí.

Otra crítica es: "el presidencialismo es ineluctablemente problemático porque opera según la regla todo al ganador... es probable que la convicción de un presidente de poseer autoridad independiente y mandato popular, lo imbuyan del sentido de poder y misión, aún si la pluralidad que lo eligió es débil” (Linz, 2013, p.16). Por su parte, en las elecciones 
parlamentarias, aunque puede resultar una mayoría absoluta de un solo partido político, por lo general, existe representación de un grupo de partidos lo que genera un poder compartido, donde es común la formación de coaliciones que permiten reflejar los intereses de los partidos políticos más pequeños.

Asimismo, entre los inconvenientes planteados en el sistema presidencialista se encuentra la prohibición o limitación de la reelección (Linz, 2013). Esta prohibición o limitación puede generar dos tipos de problemas: el primero, la rigidez del mandato el tiempo del periodo presidencial, por lo general, limita la posibilidad de que un presidente complete su programa electoral, al requerir los problemas estructurales de un país comúnmente de soluciones a mediano y largo plazo; provocando la conducción de políticas apresuradas o mal concebidas. Y, el segundo, el poder excesivo que llega a acumular que con el apoyo de las fuerzas armadas u otros grupos fácticos buscan mecanismos para permanecer en el poder provocando una ruptura del orden constitucional.

\section{LOS CONTROLES INTERORGÁNICAS EN EL PARLAMENTARISMO Y EL PRESIDENCIALISMO}

Juan Linz (como se citó por Nohlen, 2013), destacó el rol negativo del presidencialismo en América Latina y sus repercusiones en la democracia, pronunciándose a favor de la introducción del parlamentarismo ${ }^{8}$ en ${ }^{8}$ El parlamentarismo es la modalidad dominante en Europa y el Caribe y cuenta con las características siguientes: 1 . Ejecutivo bicéfalo conformado por el jefe de Estado y el jefe de gobierno, la primera en manos de un Rey o presidente y la segunda en manos de un premier; 2. El titular del Ejecutivo no es elegido de manera directa, en los países monárquicos el cargo es hereditario y en el resto son elegidos indirectamente a través del Parlamento; 3. El titular del Ejecutivo solo puede culminar su mandato con anticipación por alta traición, mientras que en el monárquico por muerte o abdicación; 4. El titular del Ejecutivo participa en las funciones que le están implícitas por razones de su cargo de manera formal, finiquitándolas y legitimándolas, enmarcándose en un poder neutro con un rol equilibrador, mediador y ceremonial; 5. Existe un órgano colegiado denominado generalmente Consejo de Ministros, reconocido constitucionalmente como órgano autónomo y con atribuciones propias, conformado por un Primer Ministro y Ministros que provienen del partido ganador de las elecciones parlamentarias; 6. El Parlamento es considerada como expresión del poder soberano del pueblo; 7. El Primer Ministro es el responsable de la administración pública y media entre el la región. Siendo este un ejemplo de las constantes comparaciones entre ambos tipos de gobierno.

A favor del parlamentarismo se encuentra que este cuenta con un mayor control hacia la función Ejecutiva que los sistemas presidencialistas. Esto responde a que, en el parlamentarismo, se sostiene la creencia que la Asamblea o Parlamento es el depositario de la soberanía popular, por lo que, el Gobierno debe contar con la confianza del Legislativo.

Según el profesor Villabela Armengol (2008), la confianza del Legislativo hacia el Ejecutivo tiene que expresarse en dos sentidos:

[U]na legitimación inicial que se produce al aprobarse por el Parlamento el nombramiento del Primer Ministro y el resto del gobierno, acto que algunas constituciones legitiman mediante una investidura formal; y una confianza de ejercicio que se patentiza porque no se interpongan o prosperen, en caso de plantearse, los diferentes mecanismos de control político con que cuenta el Legislativo (p.34).

En ese sentido, la acción controladora del Parlamento puede materializarse a través de diferentes mecanismos, los que resultan determinantes para exigir la responsabilidad política del Ejecutivo. No obstante, algunos de estos mecanismos no se encuentran contemplados dentro de los gobiernos presidencialistas. Es para contrarrestar la figura predominante del presidente en este tipo de gobiernos, que existe una tendencia de introducir elementos de control propios del régimen parlamentario en los sistemas presidencialistas.

titular del Ejecutivo y el Consejo de Ministros y representa al gobierno ante el Parlamento; 8. El gobierno tiene que contar con la confianza del Legislativo y está sometido a su control en todo momento, la que puede materializarse a través de diferentes mecanismos que permiten exigir la responsabilidad política; 9. En compensación a los mecanismos de control, el titular del Estado puede disolver el Parlamento cuando se dan diferentes supuestos que provocan la inestabilidad política; $10 . \mathrm{La}$ relación entre el Legislativo y el Ejecutivo conlleva en muchas ocasiones a la necesidad de conformar pactos para hacer gobierno y la posibilidad latente de que ambos órganos no culminen su mandato (Villabela, 2008, p. 31-37). 
El control en el parlamentarismo hacia el Gobierno se realiza en todo momento, materializandose a través de interpelaciones, comisiones de investigación o bien la moción de censura y confianza, estos últimos considerados los más importantes para la exigencia de la responsabilidad política y reestructuración del gobierno.

La moción de censura se produce a iniciativa del Parlamento y consiste en el cuestionamiento al actuar de un ministro o del Consejo de Ministros en pleno mediante una votación en la que se desaprueba una decisión adoptada o la política que se ha seguido. Ante esta situación la o el ministro o la institución de Gobierno debe dimitir provocando consecuentemente una reestructuración. Cuando la moción de censura es rechazada, usualmente se prohíbe su tramitación durante un periodo de tiempo determinado.

La cuestión de confianza, es un mecanismo que se produce a iniciativa del Gobierno y que consiste en solicitar al Parlamento una votación sobre un programa político o un proyecto legislativo, a fin de contar claramente con el apoyo del Parlamento. La cuestión de confianza es utilizada en circunstancias difíciles como un instrumento de presión del Gobierno para comprobar el respaldo que posee bajo la amenaza de provocar una crisis, ya que, en caso de desaprobación se produce la renuncia y recomposición del Consejo de Ministros. Es por esta razón que, algunos estudiosos del tema la han denominado "un arma de amenaza que puede llevar al suicidio" (Villabela, 2008, p.36).

Igualmente, en el parlamentarismo el titular de Ejecutivo, generalmente a propuesta del primer ministro, puede disolver el Parlamento cuando se dan determinados supuestos que provocan una inestabilidad política. Por lo antes expuesto es que, los que apoyan el parlamentarismo consideran que en virtud de la relación entre el Legislativo y Ejecutivo, existe la necesidad de conformar pactos que permitan la posibilidad a ambos órganos de culminar su mandato, promoviendo de esta forma el diálogo y los consensos que permitan una forma de gobierno estable. No obstante, las posturas en defensa del presidencialismo sostienen lo contrario, al considerar que al no tener la posibilidad el Legislativo de influir en los asuntos internos del Ejecutivo y que el presidente del Ejecutivo no pueda disolver el Congreso, se genera mayor nivel de estabilidad política.

Sin embargo, en el presidencialismo, el Parlamento también ejerce control sobre las actividades de Gobierno y puede deducir la responsabilidad política del presidente del Ejecutivo a través del juicio político (impeachment). En lo relacionado al control sobre las actividades de Gobierno, usualmente el Legislativo cuenta con mecanismos generales, es decir, la ratificación de ciertas decisiones del titular del Ejecutivo; interpelaciones; recibir informes del presidente o de sus secretarios de Estados; la aprobación del presupuesto, entre otras, las que son propias de los controles inter orgánicos. Aunque, en el presidencialismo, el titular del Ejecutivo bajo ninguna circunstancia puede disolver al Parlamento, aunque cuenta con algunas atribuciones de control sobre el Legislativo, siendo la más destacada el veto presidencial.

E1 presidencialismo predominante en Estados Unidos de América y América Latina, se basa en la separación de poderes y los checks and balances entre las tres funciones básicas del Estado, aunque esta figura ha tenido mejores resultados y mayor estabilidad en el primero. Entre los elementos que justifican el mayor grado de efectividad del presidencialismo norteamericano, se encuentra que: ninguna rama de la clásica tripartición del poder puede dominar con autoridad absoluta a las otras; el federalismo norteamericano cuenta con un gobierno central fuerte, sin usurpar las competencias estatales legales, financieras y sociales; y, la perdurabilidad en el tiempo de su texto constitucional y la confianza del pueblo norteamericano en el mismo (Ortiz, 2004).

En el caso de América Latina, el presidencialismo llegó luego de un proceso independentista, en el que, a pesar de intentar encontrar un sistema de gobierno adecuado, existía una alta polarización ideológica $\mathrm{y}$ actores políticos con perfiles personalistas y caudillistas. América Latina adoptó la separación de poderes y los mecanismos de controles mutuos, no obstante, el sistema norteamericano dio un alto 
protagonismo a la autoridad judicial dotándole de la debida independencia ${ }^{9}$; lo que se evidencia con la sentencia dictada en el caso Marbury vs. Madison en $1803^{10}$. En el caso de América Latina, por lo general, los textos constitucionales concibieron una función Judicial con un poder nulo o débil ante las funciones Ejecutiva y Legislativa, sin fuerza de decisión y sometida a las leyes emitidas por el Legislativo ${ }^{11}$. Finalmente, las constituciones latinoamericanas debido a las luchas ideológicas existentes al momento de la independencia, no han corrido con la misma suerte que el texto constitucional de Norteamérica, al contrario, han sido constantemente cambiadas en su totalidad o reformadas parcialmente; lo que no permite que exista confianza del pueblo en la Norma Fundamental, sobre todo, cuando las mismas provienen de procesos constituyentes carentes de legitimidad por ser representativos de las élites políticas.

En resumen, el presidencialismo es una forma de gobierno altamente cuestionada, aunque existen posiciones doctrinales que defienden su organización. Es por esta razón que, es importante determinar, si en el caso de Honduras las falencias identificadas doctrinalmente con respecto al presidencialismo se han consolidado o al contrario ha producido los efectos positivos esperados.

\footnotetext{
${ }^{9}$ Se destacan como principales características: el nombramiento y la carrera profesional de jueces debe basarse en el mérito; la inamovilidad es un elemento relevante de la independencia judicial; la remuneración está garantizada y es proporcional a la dignidad de la profesión y a las responsabilidades que se asumen; $\mathrm{y}$, se prevén sanciones contra quienes pretendan influir en dicho ámbito.

${ }^{10} \mathrm{El}$ caso Marbury vs. Madison un proceso judicial abordado ante la Corte Suprema de los Estados Unidos y resuelto el 24 de febrero de 1803, en el que la Corte Suprema de ese país dictó sentencia aplicando la Constitución como ley suprema y desaplicando la ley contraria a la constitución en un caso concreto, siendo por tanto considerada nula. Se considera el caso más importante de la jurisprudencia estadounidense, no por el asunto específico tratado, que no era menor, sino por los principios que estableció. La sentencia afirma la capacidad de los tribunales de realizar control de constitucionalidad, es decir juzgar la conformidad de la ley con la Constitución y para abrogar, implicándolas, aquellas que pudieran contravenirla. Este principio instituye la atribución más importante de los tribunales estadounidenses, y hace de ellos los primeros tribunales constitucionales de la historia.

${ }^{11}$ Aunque el carácter dogmático de la teoría de la división de poderes y su significado histórico identifica la independencia del Poder Judicial en su aspecto orgánico y funcional ónticamente se aprecia una sumisión frente a los otros poderes.
}

\section{EL PRESIDENCIALISMO EN HONDURAS}

Honduras ha adoptado el presidencialismo como forma de gobierno, la que ha sido claramente expuesta a lo largo de su historia constitucional y que tiene sus primeros pasos con la independencia centroamericana el 15 de septiembre de 1821. El modelo político adoptado por Centroamérica para emitir su Constitución Federal de 1824, se inspiró en el sistema federal y presidencialista consagrado en la Constitución de los Estados Unidos de 1787, cuyo rasgo distintivo fue la titularidad del Ejecutivo a cargo de un presidente de la República Federal nombrado por el pueblo de todos los Estados de la Federación y sustituido por un vicepresidente, igualmente nombrado, modelo que fue adoptado por la Constitución de Honduras de 1825 bajo la titularidad del Ejecutivo a cargo de un jefe o vice jefe nombrados popularmente. En las subsiguientes Constituciones Políticas, se consagra que la forma de gobierno estará a cargo de un presidente de la República, electo directamente por el pueblo.

Para algunos analistas hondureños la adopción de este modelo constituyó "una funesta equivocación, de consecuencias gravísimas para la futura vida institucional de nuestros países" (Pineda, 1977, p. 21). Pese a que, luego de la independencia, la región centroamericana compartía las consecuencias de la herencia colonial, marcada por un contexto de crisis económica, con bajo desarrollo de fuerzas productivas y malas comunicaciones entre los países; a ello puede atribuirse a que el sistema federal en las colonias españolas tuvo poco éxito ${ }^{12}$. Además del sistema federal adoptado por Centroamérica, se encuentra la adopción de la forma de gobierno presidencial, que provocó la lucha de diferentes actores políticos con distintas ideologías por llegar y adoptar la política que consideraran más apropiada de acuerdo a sus ${ }^{12} \mathrm{E} 1$ fracaso de los sistemas federales en las colonias españolas es atribuido a los procesos de colonización e independencia existentes, en virtud que, la corona española dividió sus territorios en virreinatos que establecieron sus propias estructuras locales, lo que impidió establecer una sola estructura de Gobierno. Además de ello, en las colonias españolas también existian capitanias e intendencias en las provincias, las que se encontraban al mando de generales, coromeles, etc. que permitió la existencia de militares caudillos. Mientras que, en Brasil, en donde el sistema federal pudo consolidarse, a pesar de dividirse el territorio en capitanias hereditarias, la corona portuguesa tomó directamente el control de su colonia, a través del nombramiento de un gobernador general o capitán general. 
tendencias e ideologías políticas. Esta situación generó inestabilidad política y social, complicando aún más la voluntad de los Estados Miembros de resolver los serios problemas económicos de forma conjunta y con cierto grado de descentralización, principalmente, al haberse afianzando las tendencias localistas (heredadas de nuestro proceso colonial) y consecuentemente las diferencias ideológicas y sociales.

Conforme al artículo 4 de la actual Constitución de la República de 1982 : "La forma de gobierno es republicana, democrática y representativa. Se ejerce por tres poderes: Legislativo, Ejecutivo y Judicial, complementarios e independientes y sin relaciones de subordinación." Si bien, no establece de manera expresa el presidencialismo, doctrinalmente, profesores como Villabela (2008), han identificado a esta forma de gobierno como "presidencialismo puro" al reunir para este autor las características siguientes: 1. La función Ejecutiva es unipersonal, al tener el presidente la condición de jefe de Estado y de Gobierno; 2. El presidente cuenta con un amplio espectro de atribuciones en el texto constitucional; 3. Los secretarios de Estado se presentan como colaboradores del presidente, por lo que no cuentan con funciones propias, sino en el ámbito de colaboración al presidente; y, 4. El Consejo de Ministros se plantea como un ente que se reúne a iniciativa del presidente, no poseyendo atribuciones propias.

El Artículo 235 constitucional señala: "la titularidad del Poder Ejecutivo lo ejerce en representación y para beneficio del pueblo el presidente de ese poder estatal." De esta manera, en Honduras, la función Ejecutiva se prevé alrededor del presidente de la República, a quien constitucionalmente se le otorgan 44 atribuciones directas y una analógica que recoge las demás atribuciones conferidas en la Constitución y las leyes ${ }^{13}$, que lo faculta para desarrollar múltiples funciones, atendiendo el interés social relativo al orden público, seguridad interna y externa, educación, trabajo, economía, finanzas, comunicaciones, etc.

El presidente de la República es el encargado de elaborar y ejecutar políticas generales para ejecutan cumplir y hacer cumplir las leyes. Igualmente, dirige

\footnotetext{
${ }^{13}$ Cfr., artículo 245 de la Constitución de la República.
}

en su carácter de Comandante General a las Fuerzas Armadas, fortaleciendo de esta forma el poder que se le atribuye ${ }^{14}$.

También, el presidente cuenta con la potestad de legislar al otorgársele en el artículo 245 numeral 11, la atribución de "emitir acuerdos, decretos y expedir reglamentos y resoluciones conforme a la Ley", cuyo control le corresponde a la Jurisdicción de lo Contencioso -Administrativo y a la Sala de lo Constitucional de la Corte Suprema de Justicia, ambas dentro de la estructura de la función Judicial.

En el transcurso del constitucionalismo hondureño, se han ido fortaleciendo las atribuciones de la función Ejecutiva y consecuentemente el presidencialismo. Tanto es así que, la Constitución de Honduras de 1825 expresamente le otorgaba al titular del Ejecutivo 7 atribuciones y actualmente cuenta con 45 atribuciones ${ }^{15}$.

Una de las características propias del sistema presidencialista que hace la diferencia del sistema parlamentario, se encuentra en el artículo 245 numeral 5 que otorga al presidente de la República, la atribución de "nombrar y separar libremente a los secretarios y subsecretarios de Estado”. A diferencia de los sistemas parlamentarios, en Honduras el presidente de la República puede nombrar o separar a sus Secretarios de Estado sin la aprobación del Congreso Nacional ${ }^{16}$.

Por otra parte, con la transición a la democracia se establecieron nuevos límites legales para impedir las aspiraciones de continuidad de los dirigentes presidenciales. Los Asambleístas Constituyentes que

${ }^{14}$ En el numeral 16 del artículo 245 de la Constitución de la República se le faculta: Ejercer el mando en jefe de las Fuerzas Armadas en su carácter de Comandante General, y adoptar las medidas necesarias para la defensa de la República.

${ }^{15}$ Entre los cambios en las atribuciones otorgadas a la función Ejecutiva, figura la conmuta y el indulto, la que a pesar de ser una atribución de naturaleza judicial, en las primeras constituciones hondureñaas (establecer hasta que constituciones aparecían) era una atribución de la función Legislativa, pero que actualmente, conforme al artículo 245 numeral 24 , corresponde al presidente.

16 La rama Ejecutiva se divide en administración central y descentralizada. La administración central se encuentra integrada por la Presidencia de la República, las y los designados presidenciales, el Consejo de Ministros y las Secretarías de Estado. 
dieron origen a la Constitución de 1982 incluyeron la prohibición absoluta de reelección presidencial en el catálogo de las normas pétreas, disposición que surge a raíz de la creencia de que uno de los principales problemas de la vida política hondureña ha sido la predisposición de quienes han ostentado la función Ejecutiva, de prolongarse o perpetuarse en el poder. Es por ello que, en el artículo 239 de la Constitución de la República, formalmente se prohíbe prohibía la reelección y establece establecía una sanción constitucional por su violación ${ }^{17}$.

Al ser una norma de naturaleza pétrea, esta únicamente podría ser reformada por una Asamblea Nacional Constituyente. El primer intento de reforma de dicho artículo se produjo el 26 de mayo de 2009, cuando el presidente de la República emitió el Decreto PCM 05-2009, que convocaba al pueblo hondureño a una amplia consulta popular ${ }^{18}$.

Este Decreto de acuerdo a la Comisión de la Verdad y la Reconciliación (2011) ${ }^{19}$ fue emitido con base en "una serie de violaciones a la normativa hondureña" (p.181). A pesar de ser ámbitos totalmente distintos, existe una tendencia de identificar tanto por la clase política como por la sociedad, el tema de una Asamblea Nacional Constituyente con el de la reelección presidencial; situación que se vio reflejada

\footnotetext{
${ }^{17}$ El artículo 239 erróneamente fue declarado por la Sala de lo Constitucional como inconstitucional y consecuentemente inaplicable: El ciudadano que haya desempeñado la titularidad del Poder Ejecutivo no podrá ser presidente o Designado. El que quebrante esta disposición o proponga su reforma, así como aquellos que lo apoyen directa o indirectamente, cesarán de inmediato en el desempeño de sus respectivos cargos, y quedarán inhabilitados por diez (10) años para el ejercicio de toda función pública.

${ }^{18}$ El 23 de marzo de 2009, el presidente en Consejo de Ministros aprueba el Decreto Ejecutivo PCM-05-2009, en el cual se ordena la realización a más tardar el último domingo del mes de junio de 2009, de una amplia consulta a nivel nacional para que la ciudadanía pueda expresar estar de acuerdo o no con la convocatoria de una Asamblea Nacional Constituyente que dicte y apruebe una nueva Constitución de la República. La consulta consistía en la pregunta siguiente: ¿Está de acuerdo que en las elecciones generales de noviembre de 2009 se instale una cuarta urna para decidir sobre la convocatoria a una asamblea nacional constituyente que apruebe una nueva Constitución política? (Comisión de la Verdad y la Reconciliación, 2011, 131-132

${ }^{19}$ La Comisión de la Verdad y la Reconciliación fue creada mediante Decreto No. PCM-011-2010 Fue dotada de independencia funcional, administrativa, técnica y financiera la cual tiene como objetivos esclarecer los hechos ocurridos antes y después del 28 de junio de 2009.
}

con el golpe de Estado producido el 28 de junio de 2009, el que además de la intención de reformar las disposiciones referentes a la prohibición de reelección presidencial también respondió al alto nivel de confrontación entre la función Ejecutiva y Legislativa.

El segundo intento de reforma, se produce en el 2015 cuando la Sala de lo Constitucional de la Corte Suprema de Justicia declaró la inaplicabilidad del artículo 42 numeral 5; artículo 239; artículo 4 último párrafo y el artículo 374 de la Constitución de la República en lo referente a la prohibición para ser nuevamente presidente de la República la o el ciudadano que lo haya desempeñado bajo cualquier título. El fundamento legal de la Sala de lo Constitucional consistió en considerar que la prohibición de la reelección presidencial vulnera los derechos comprendidos en el marco del sistema internacional de protección de derechos humanos, aun y cuando se sabe, que no existe un derecho humano especifico a la reelección. Con ello, se evidenció la influencia que el Ejecutivo ejerce sobre el resto de funciones básicas del Estado, al lograr la modificación constitucional a través de la función Judicial de principios considerados como absolutos en nuestro constitucionalismo.

Actualmente, la reelección presidencial bajo la fundamentación controvertida de la sentencia relacionada es fácticamente permitida y mientras el pueblo hondureño no sea consultado carecerá de legitimidad.

Otro aspecto que destacar en el ejercicio del poder en Honduras es la centralización del poder en el presidente de la República, un ejemplo, es la conformación del Consejo Nacional de Defensa y Seguridad, cuyo sustento se encuentra en el artículo 287 constitucional y su organización y funcionamiento es desarrollado por la Ley Especial del Consejo Nacional de Defensa y Seguridad ${ }^{20}$. De acuerdo a la Ley en mención el Consejo es el máximo órgano permanente, encargado de rectorar, diseñar y supervisar las políticas generales en materia de seguridad, defensa nacional e inteligencia.

\footnotetext{
${ }^{20}$ Decreto No. 239-2011 de fecha 08 de diciembre de 2011, publicado en el Diario Oficial La Gaceta No. 32,692 de fecha 12 de diciembre de 2011.
} 
La aprobación de este Decreto es altamente cuestionado, sobre todo por su implicación en el principio de separación de poderes, al considerar que al estar presidido por el titular del Ejecutivo e integrado por los titulares de las tres funciones básicas del Estado y por el Fiscal General de la República en su condición de titular del Ministerio Público, y los Secretarios de Seguridad y Defensa crea una relación de subordinación de la principal institucionalidad hacia el presidente de la República ${ }^{21}$.

En todo orden democrático debe existir la posibilidad de exigir responsabilidad a las y los gobernantes y altas autoridades estatales por los actos realizados en el ejercicio de su cargo y la concentración de poder, no debe ser óbice para ello, al contrario es la puerta que abre los controles. Es por ello que, constitucionalmente, a la par de sus atribuciones propias, la función Legislativa $\mathrm{y}$ Judicial, así como algunos órganos constitucionales autónomos, contemplan atribuciones de control, impulsando de esta manera, los checks and balances y la colaboración interorgánica.

La función Legislativa ${ }^{22}$, es concebida doctrinalmente como la representación popular al encarnar la voluntad general a través de las diferentes representaciones con las que cuenta. Como se mencionó anteriormente, una de las principales críticas de los sistemas presidencialistas es la doble legitimidad democrática que se ejerce entre la función Ejecutiva y Legislativa, lo que se evidencia si se revisa que en el texto constitucional hondureño ambas funciones cuentan con el mismo número de

\footnotetext{
${ }^{21}$ El Consejo se encuentra integrado por: El Presidente de la República, quien lo preside; El Presidente del Congreso Nacional; El Presidente de la Corte Suprema de Justicia; El Fiscal General; El Secretario de Estado en el Despacho de Seguridad; y, El Secretario de Estado en el Despacho de Defensa Nacional.

${ }^{22}$ Conforme al artículo 189 la función Legislativa se ejerce por un Congreso de Diputados, es decir, es unicameral, a diferencia de los sistemas bicamerales que son ejercidos por el senado y la cámara de representantes. A la función Legislativa de acuerdo a la normativa hondureña le corresponde la emisión de las leyes a través de las cuales se concretan las decisiones sobre el desarrollo económico, social, político y cultural. De acuerdo a la Ley Orgánica del Poder Legislativo establece como órganos del Congreso: El pleno de Diputados y Diputadas; la junta directiva; la comisión permanente; las bancadas; las comisiones legislativas; la gerencia legislativa; y la pagaduría especial del poder legislativo. Actualmente el Congreso Nacional se encuentra conformado por 29 comisiones permanentes, que se integran por grupos de congresistas encargados de temas específicos.
}

atribuciones. Sin embargo, en las constituciones precedentes la función Legislativa contaba con mayores atribuciones que el resto de funciones ${ }^{23}$.

De esta manera, al ser considerada la función Legislativa la representación popular de la voluntad general, está obligada a ejercer verdaderos mecanismos de control sobre el Ejecutivo, contando para ello de autonomía parlamentaria, con la capacidad de dotarse de sus propias normas de funcionamiento ${ }^{24}$, así como con funciones de control hacia el Ejecutivo ${ }^{25}$, siendo probablemente las más importante de todas el juicio político.

En la historia reciente de Honduras, como ya ha mencionado se han presentado situaciones de conflictividad entre el Legislativo y el Ejecutivo, que desembocaron en el golpe de Estado del 2009.

El Informe titulado Hallazgos y Recomendaciones: Para que los hechos no se repitan de la Comisión de la Verdad y Reconciliación de Honduras (2011), señaló

${ }^{23}$ A pesar de la doble legitimidad criticada por la doctrina, hay que reconocer que en la realidad y en el Estado liberal, la sociedad política difícilmente representa la voluntad popular, sino que representa a sectores determinados, especialmente a los sectores investidos de poder económico y político, por lo que puede decirse, que estas dos funciones estatales pueden trabajar armónicamente siempre y cuando estén representando a un mismo sector económico o bien existan negociaciones de convivencias entre las partes que integran dicho sector. ${ }^{24}$ En Honduras se conoce como Ley Orgánica del Poder Legislativo, la que hace un desarrollo inmediato y es únicamente aplicable a las y los congresistas.

25 Conforme al artículo 205 de la Constitución de la República, el Congreso Nacional cuenta con atribuciones de control hacia el Ejecutivo, como: Conceder o negar permiso al Presidente y designados a la Presidencia de la República para que puedan ausentarse del país por más de quince días; aprobar o improbar los contratos que lleven involucradas exenciones, incentivos y concesiones fiscales o cualquier otro contrato que haya de producir o prologar sus efectos al siguiente período de gobierno de la República; aprobar o improbar la conducta administrativa Ejecutivo; interpelar a los Secretarios de Estado y a otros funcionarios del gobierno central, organismos descentralizados, empresas estatales y cualquier otra entidad en que tenga interés el Estado; autorizar al Ejecutivo la salida de tropas de las Fuerzas Armadas para prestar servicios en territorio extranjero; aprobar o improbar los tratados internacionales que el Ejecutivo haya celebrado; aprobar anualmente el Presupuesto General de Ingresos y Egresos tomando como base el proyecto que remita el Ejecutivo; aprobar los presupuestos de las instituciones descentralizadas; aprobar o improbar los empréstitos o convenios que se relacionan con el crédito público celebrados por el Ejecutivo; aprobar o improbar la liquidación del Presupuesto General de la República; autorizar al poder Ejecutivo para enajenar bienes nacionales; $y$, probablemente la más importante de todas, realizar el juicio político. 
que una de las razones para que se diera el golpe de Estado de 2009, fue la ausencia de una fórmula constitucional para el sometimiento de presidente o un alto funcionario a una investigación o a una destitución (p.399) ${ }^{26}$. Razón por la que, la Comisión recomendó que se regulara la institución del juicio político o separación del cargo de los miembros del Ejecutivo.

Conceptualmente, el juicio político representa el cuestionamiento que realiza el Congreso sobre determinados altos funcionarios del Estado, cuando éstos incurren en una infracción de la Constitución en el ejercicio de sus funciones. Su objetivo principal consiste en separar a dicho funcionario del cargo que ocupa, y eventualmente, inhabilitarlo para la función pública durante un tiempo determinado.

En seguimiento a dicha recomendación, el 23 de enero de 2013 se aprobó el Decreto No. 231-2012, mediante el cual se reformó la Constitución de la República agregando en el artículo 205 numeral 15 la facultad del Congreso Nacional de realizar el juicio político, el que de acuerdo al artículo 234 de la Constitución procede contra el Presidente de la República y Designados Presidenciales, Magistrados de la Corte Suprema de Justicia, Diputados del Congreso Nacional y Parlamento Centroamericano, Corporaciones Municipales y todos los servidores públicos electos por el Congreso Nacional. El 5 de abril de 2013 mediante Decreto No. 51-2013, se aprobó la Ley Especial de Juicio Político que establece entre las causales del juicio político, la denuncia grave en el desempeño en su cargo; actuaciones contrarias a la Constitución de la República o el interés nacional; $\mathrm{y}$, negligencia, incapacidad o incompetencia para el desempeño del cargo.

\footnotetext{
${ }^{26}$ Hasta el año 2002 la Constitución de la República tenía incorporada la figura del antejuicio. El régimen de inmunidades consistía en que, si se sospechaba que un alto funcionario hubiese incurrido en una conducta contraria al buen desempeño de su cargo, en un delito político o común, como estaba revestido de inmunidades, se solicitaba al Congreso que lo declarara con lugar a formación de causa, y de esta forma despojarlo de la protección de la inmunidad. Si lo declaraba no se estaba declarando su culpabilidad, ya que el Congreso no tenía la facultad de juzgar al alto funcionario y solo se pronunciaba a la existencia de indicios racionales para someterlo a juzgamiento. Una vez que el Congreso Nacional se pronunciaba y declaraba que había indicios racionales, el alto funcionario pasaba a ser juzgado por un juez especial donde la Corte Suprema nombraba a un magistrado para que actuara como juez de primera instancia y el resto de los magistrados, en apelaciones.
}

Por su parte, la función Judicial es considerada un órgano de garantía de los derechos fundamentales, necesariamente independiente del resto de funciones básicas del Estado. Constitucionalmente, la Corte Suprema de Justicia, únicamente cuenta con 12 atribuciones frente a 45 atribuciones otorgadas a la función Ejecutiva y Legislativa. Desde la Constitución Federal de 1824, se planteó una separación de poderes en la que las funciones de gobierno (Ejecutivo y Legislativo) tenían fuerza propia, mientras que la función Judicial era concebida como un poder nulo, que no tenía más fuerza que su propia decisión y con estricto sometimiento a las leyes emitidas por el Congreso Nacional. Esto es evidente, en las pocas atribuciones con las que la función Judicial contaba desde el inicio de la historia constitucional hondureña, así como, en la ausencia de mecanismos que garantizarán la independencia de los jueces y magistrados principalmentea través de suinamovilidad. Una prueba de ello, es que la creación de los tribunales no dependía de la función judicial, sino que dependía del Legislativo. Igualmente, el titular del Ejecutivo en varios de nuestros textos constitucionales, contó con la atribución de nombramiento de jueces de primera instancia y magistrados de la Corte de Apelaciones.

A pesar de ello, la Sala de lo Constitucional de la Corte Suprema de Justicia a través de la sentencia del recurso de inconstitucionalidad No. SCO-696$2012^{27}$ reconoce que de acuerdo a la doctrina jurídica contemporánea la función Judicial es un órgano de control frente a los otros poderes, por lo que, señala "que desde el punto de vista de la separación de poderes, el Poder Judicial no se encuentra subordinado a ninguno de los otros Poderes del Estado, sea el Legislativo o el Ejecutivo" ${ }^{28}$.

\footnotetext{
${ }^{27}$ Recurso de inconstitucionalidad contra la Ley del Consejo de la Judicatura y la Carrera Judicial, aprobada mediante el Decreto Legislativo No. 219-11, de fecha 25 de noviembre de año 2011.

${ }^{28} \mathrm{En}$ Honduras, la función judicial se encuentra conformada por una Corte Suprema de Justicia, Cortes de Apelaciones, Juzgados y Tribunales con competencia exclusiva en zonas del país sujetas a regímenes especiales, siendo la Corte Suprema de Justicia el máximo órgano jurisdiccional. Anteriormente, la Corte Suprema de Justicia en Honduras, únicamente estaba integrada por tres salas: La Sala de lo Penal, la Sala de lo Civil y la Sala Laboral- Contencioso Administrativo, en razón de esta organización, los recursos de inconstitucionalidad de leyes eran conocidos por los Coordinadores de cada Sala. Es a partir del año 2000 a través del Decreto No. 162-2000, emitido el 20 de diciembre del 2000 que se crea la Sala de lo Constitucional, además, aumentando el
} 
Entre los aspectos que más duda genera en cuanto a la subordinación de la función Judicial hacia el resto de funciones, es la forma de elección de las y los miembros de la Corte Suprema de Justicia. En el caso de Honduras, a pesar de que, a lo largo de su historia constitucional se han hecho diferentes reformas sobre la forma de elección de las y los magistrados ${ }^{29}$, aun no se ha logrado una verdadera independencia de ese poder del Estado. Llama la atención que la Sala de lo Constitucional en sentencia proferida en del recurso de inconstitucionalidad No. SCO-696-2012 considera la forma de elección como un mecanismo de control y limitativo de las funciones de gobierno sobre la función judicial ${ }^{30}$.

Una de las principales atribuciones de control otorgada a la función Judicial y aporte del constitucionalismo norteamericano, es el control judicial o el judicial review, con el que, como ya se ha mencionado, se dio fuerza a la función Judicial frente al Legislativo y Ejecutivo. En el caso de Honduras, el recurso de inconstitucionalidad se estableció por primera vez a través de la Constitución de 1894 y actualmente es potestad de la Sala de lo Constitucional de la Corte Suprema de Justicia.

número de magistradas y magistrados que la integran pasando de 9 a 15 integrantes. Cada Sala está integrada por tres magistrados a excepción de la Sala de lo Constitucional que cuenta con cinco integrantes, y la presidencia de la Corte Suprema de Justicia que ostenta las funciones administrativas, pudiendo integrarse a cualquiera de las Salas en caso de ausencia o impedimento de alguno de los miembros. Asimismo,

${ }^{29}$ Actualmente, el proceso de selección de las y los candidatos a magistrados depende de una Junta Nominadora conformada por 7 sectores de la sociedad, la que propone una nómina de 45 candidatas y candidatos y el Congreso Nacional nombra a 15 como magistradas y magistrados de la Corte Suprema de Justicia, por un periodo de 7 años, los que podrán ser reelectos.

${ }^{30}$ Actualmente, correponde a la Sala de lo Constitucional de la Corte Suprema de Justicia su conocimiento. Una de las críticas permanentes que se le ha hecho a la Corte Suprema de Justicia, es la influencia que los poderes políticos y económicos del país ejercen sobre la misma. La politización en la función Judicial se denota cuando las altas dirigencias de los partidos políticos a través de sus representaciones en el Congreso Nacional escogen a las y los magistrados. Sobre todo, si se toma en cuenta, que por lo general el partido político en funciones en el Ejecutivo cuenta con un mayor número de representantes en el Congreso Nacional. Actualmente, la función judicial y principalmente la Corte Suprema de Justicia sufre de una falta de confianza de la sociedad, esto debido a que para algunos esta manejado por los distintos poderes económicos y políticos del país.

\section{CAMBIOS PARA LA MEJORA DEL CONTROL Y EJERCICIO DEL PODER EN LA FORMA DE GOBIERNO DE HONDURAS}

No existe una forma de gobierno única que se adapte al contexto político y social de todos los países de la región. Razón por la que, en el caso de Honduras, no se podría sostener que el parlamentarismo solucionaría los problemas existentes. En el presente artículo, se concluye que, más allá del sistema político presidencialista adoptado en las constituciones hondureñas a lo largo de su historia, actualmente uno de los mayores problemas es la falta de independencia y control de la función Legislativa y Judicial hacia la función Ejecutiva.

Es por ello que, es imprescindible realizar cambios estructurales en la forma de organización y funcionamiento de las funciones básicas del Estado, que garanticen la independencia de las tres funciones básicas y el efectivo ejercicio del control interinstitucional. En el caso del Legislativo se requiere un marco regulatorio que regule de forma completa $\mathrm{y}$ clara el procedimiento de creación, reforma y derogación de las leyes y en especial, el de reforma de las normas constitucionales de naturaleza intangible. Actualmente, la Ley Orgánica del Poder Legislativo cuenta con una escasa regulación del proceso Legislativo y del funcionamiento interno del Congreso Nacional, permitiendo un margen de decisión muy amplio al titular del Congreso Nacional y en algunos casos en la toma de decisiones para el funcionamiento interno (como la celebración de sesiones plenarias, la integración de comisión especiales de investigación u otras comisiones nombradas en el curso del proceso legislativo $)^{31}$.

31 El presidente del Congreso Nacional conforme a la Ley Orgánica del Poder Legislativo actualmente cuenta veinticuatro (24) atribuciones frente a las cinco (5) que corresponden a la Junta Directiva como órgano colegiado con representación de los diferentes partidos políticos. Entre las atribuciones otorgadas se encuentran: conceder la palabra y suspender el uso de la misma; ejercer la administración del Congreso Nacional; aprobar la estructura organizativa para el adecuado funcionamiento del Congreso Nacional y sus respectivos manuales; nombrar y sustituir los integrantes de las Comisiones Legislativas; crear Comisiones Legislativas Especiales; establecer la agenda para las sesiones del pleno, modificándolas cuando fuere conveniente; entre otras. 
Esto provoca un ambiente de mucho autoritarismo, ingobernabilidad interna e incluso inseguridad jurídica, especialmente si se toma en cuenta que por lo general la mayoría de las y los diputados pertenecen al partido político en funciones en el Ejecutivo, por lo que, hay un mayor nivel de influencia del presidente de ese poder en los procedimientos Legislativos.

En lo que respecta a la función Judicial, es imprescindible dotarla de la misma fuerza que las funciones Legislativa y Ejecutiva. En la actualidad, el mayor punto de debilidad pasa por el cuestionamiento a su independencia, razón por la que, se debe fortalecer la carrera judicial estableciendo su acceso mediante un sistema de oposición que cuente con remuneraciones justas y análogos (según el puesto de trabajo), a los de la función Legislativa y Ejecutiva, con el objetivo de garantizar la estabilidad judicial y el nombramiento de personas con vocación y alto nivel técnico en las diferentes posiciones que conforman la función judicial. Asimismo, es imprescindible replantear la forma de elección de las y los magistrados de la Corte Suprema de Justicia, la que dependerá en una medida considerable del grado de fortalecimiento de la Carrera Judicial, pudiendo plantearse la posibilidad que las y los magistrados sean electos entre los mismos miembros de la Carrera Judicial, entre aquellos que cuenten con mayor experiencia y años de carrera. Con respecto a la conformación de la jurisdicción constitucional, debe plantearse la posibilidad de crear un juez constitucional independiente de la función Judicial, como un Tribunal Constitucional que garantice un control político y de constitucionalidad, particularmente para dirimir los conflictos entre las funciones básicas del Estado y órganos autónomos.

En cuanto a la función Ejecutiva, países como Perú han adoptado mecanismos propios del parlamentarismo en su forma de gobierno. El más destacado de ellos, es la inclusión del presidente del Consejo de Ministros, el que cuenta con la atribución de la opinión consultiva ${ }^{32}$, el voto deliberativo ${ }^{33}$ y la 32 "Opinión ilustrativa es la que formula el Consejo de Ministros como respuesta a una consulta que el presidente le formula libremente, es decir, sin estar obligado a realizarla" (Cairo, s.f.).

33 "El voto deliberativo es el acuerdo aprobatorio del Consejo de Ministros que requieren determinados actos presidenciales para tener validez. Según la Constitución vigente, este acuerdo es necesario para la aprobación de los proyectos de ley que el Presidente de la refrendación ministerial ${ }^{34}$. De esta manera, Perú ha dotado de herramientas al Consejo de Ministros para controlar la actividad presidencial. Asimismo, en la forma de Gobierno peruana el Congreso puede hacer efectiva la responsabilidad respecto del Consejo de Ministros mediante el voto de censura que genera el deber de renunciar de todos sus miembros ${ }^{35}$. Por su parte, en Estados Unidos de América, modelo que inspiró el presidencialismo en la región, el presidente presenta y nomina a los miembros que integrarán su Gabinete ante el Senado, el que por mayoría simple ratifica sus nombramientos. Honduras, no contempla ninguno de estos dos mecanismos de control, por lo que, podría considerarse la ratificación de los Secretarios de Estado por el Congreso Nacional, con el objeto de que exista una mayor necesidad de consensos entre las fuerzas políticas del país.

\section{CONCLUSIONES}

- La forma de gobierno adoptada en Honduras es un sistema presidencialista cuyo rasgo identificatorio es el protagonismo excesivo de la figura del titular del Ejecutivo y la falta de controles para frenar los desequilibrios y excesos de poder, por lo que, se precisa introducir cambios constitucionales que den mayor fuerza a la función Legislativa y Judicial para que puedan ejercer un efectivo control político sobre el ejercicio del titular Ejecutivo, complementándolo con los mecanismos de control popular a través del referendo revocatorio.

República somete al Congreso (artículo 125 inciso 1), de los decretos legislativos y los decretos de urgencia (artículo 125 inciso 2), de los mensajes presidenciales dirigidos al Congreso, salvo el primer de ellos (artículo 118 inciso 7), del nombramiento de embajadores y ministros plenipotenciarios (artículo 118 inciso 12), de los decretos que declaran los estados de excepción (artículo 137), y de los proyectos de ley, decretos y resoluciones que dispone la ley (artículo 125 inciso 2). Mediante el voto consultivo el Consejo responde a una consulta que el presidente se encuentra obligado a formularle, sin embargo, el resultado de la consulta no es vinculante, es decir, el presidente" es libre de seguir o no la opinión del Consejo" (Cairo, s.f.).

${ }^{34} \mathrm{El}$ artículo 120 de la Constitución señala que son nulos los actos del presidente de la República que carecen de refrendación ministerial.

${ }^{35} \mathrm{El}$ artículo 132 de la Constitución establece que el Congreso hace efectiva esta responsabilidad respecto del Consejo mediante el voto de censura o el rechazo de la cuestión de confianza. Según dispone el artículo 133 del mismo texto constitucional, tanto la aprobación de la censura del presidente del Consejo de Ministros como el rechazo de la cuestión de confianza planteada por este funcionario determinan la crisis total del gabinete, es decir, generan el deber de renunciar para todos los ministros. 
- Para que un sistema democrático pueda consolidarse en cualquier parte de mundo, se requiere el fortalecimiento del mandato constitucional y legal, así como de su independencia de los órganos autónomos de control existentes, como el Tribunal Superior de Cuentas, Ministerio Público, Comisionado Nacional de los Derechos Humanos y el Instituto de Acceso a la Información Pública, con el propósito de garantizar un control efectivo sobre las funciones básicas del Estado.

\section{REFERENCIAS BIBLIOGRÁFICAS}

- Villabela Armengol, C. (2008) Las formas de gobierno en el mundo. Un estudio desde el derecho constitucional comparado de Europa, América Latina yel Caribe. México. Benemérita Universidad Autónoma de Puebla.

- Ackerman, B. (2011) La nueva división de poderes. México D.F. Fondo de Cultura Económica.

- Secretaría de Estado en los Despachos de Gobernación y Justicia. (2005). Las constituciones de Honduras. Tegucigalpa, Honduras.

- Comisión de la Verdad y la Reconciliación. (2011) Para que los hechos no se repitan: Informe de la Comisión de la Verdad y la Reconciliación. Tomo I. San José, Costa Rica. Editorama.

- Loewenstein, K. (s.f.). La Teoría de la Constitución. Recuperado de: https://es.scribd. com/doc/58663478/Teoria-de-La-Constitucionkarl-Loewenstein

- Linz, J. (2013). Los peligros del presidencialismo. Revista Latinoamericana de política comparada. Vol. No. 7. p. 11-31.

- Negretto, D. (2013). Los orígenes del presidencialismo en América Latina: Un estudio sobre el proceso constituyente de Argentina (1853 - 1860). Revista Latinoamericana de política comparada. Vol. No. 7. p. 127-168.
- Ortiz, D. (2004). La presidencia de los Estados Unidos ¿Un modelo de Poder Ejecutivo? Espacio, Tiempo y Forma. Serie V. Contemporánea. T. 16. p. 13- 66 .

- Oas.org. CIDH solicita Opinión Consultiva a CorteIDH sobre figura del juicio político. Recuperado de: http://www.oas.org/es/cidh/ prensa/comunicados/2017/161.asp c 